\title{
Estrogenic effects of flavonoid components in Xiaoyao powder
}

\author{
J.H. Chen ${ }^{1}$, N. Zhang ${ }^{1}$, Y.Q. Wang ${ }^{1}$, J.Z. Wang' ${ }^{1}$ S.X. Ji ${ }^{1}$, W.J. Dang' ${ }^{1}$, S.M. Li ${ }^{2}$ \\ and L. Feng ${ }^{2}$ \\ ${ }^{1}$ College of Jiamusi, Heilongjiang University of Chinese Medicine, Jiamusi, \\ Heilongjiang, China \\ ${ }^{2}$ First Affiliated Hospital, Jiamusi University, Jiamusi, Heilongjiang, China \\ Corresponding authors: S.M. Li / L. Feng \\ E-mail: lishaomin_I@163.com / lilan__@163.com \\ Genet. Mol. Res. 15 (1): gmr.15017500 \\ Received August 21, 2015 \\ Accepted November 9, 2015 \\ Published February 5, 2016 \\ DOI http://dx.doi.org/10.4238/gmr.15017500
}

ABSTRACT. The objective of this study was to evaluate the estrogenic effects and mechanisms of three flavonoid components in Xiaoyao powder: quercetin, kaempferol, and isorhamnetin. The drugs were used to treat estrogen receptor (ER)-positive human breast cancer MCF-7 cells, and proliferation was measured using the MTT method. The expression of proteins and mRNA of the ER subtype were measured using western blotting and real time polymerase chain reaction. The quercetin $\left(10^{-2}\right.$ $\left.\mu \mathrm{M}, 10^{-3} \mu \mathrm{M}\right)$, kaempferol $\left(100 \mu \mathrm{M}, 10^{-2} \mu \mathrm{M}\right)$, and isorhamnetin $\left(10^{-3} \mu \mathrm{M}\right)$ promoted the proliferation of MCF-7 cells, and the expression of ERa and $E R \beta$ proteins and mRNA were all increased significantly $(P<0.05)$. These effects were reversed by treatment with $0.1 \mu \mathrm{M}$ estrogen antagonist ICl182780. Three flavonoid components in Xiaoyao powder increased the expression of proteins and mRNA of ERa and ER $\beta$ and promoted the proliferation of MCF-7 cells. These estrogenic effects were mediated by the ER.

Key words: Plant estrogenic; MCF-7 cells; Xiaoyao powder; Estrogenic receptor; Flavonoid 


\section{INTRODUCTION}

Climacteric syndrome is a series of clinical symptoms with an onset near menopause in females, in which premenopausal women show reproductive dysfunction of the hypothalamopituitary-ovary due to gradual decreasing of ovary function. The estrogen level of affected women is lower, and they exhibit menopausal symptoms such as nervous and neuropathy dysfunction, cardiovascular diseases, osteoporosis, and hectic fever. The symptoms have a major impact on women's physical and mental health (Lu et al., 2001; Wei, 2009). Estrogen has been used to relieve the symptoms of menopause, but its effects on the uterus and breast are unclear and its clinical application is limited. Therefore, there is a need for an estrogen substitute without harmful side effects. Hence, the use of estrogen plants is being explored (Song and Wang, 2004). Plant estrogens have a similar structure to estrogen and could combine with the estrogen receptor and exhibit estrogen effects. They could also play roles in climacteric syndrome, osteoporosis, and senile dementia (Tang et al., 2002; Moutsatsou, 2007). The detection of active estrogen components from plant-based drugs is a popular research topic. These active components include flavonoids, isoflavones, coumarins, lignans, and triterpenesm, with most studies focusing on flavonoids. Xiaoyao powder is considered an effective treatment for climacteric syndrome and consists of bupleurum, angelica sinensis, poria cocos, atractylods, glycyrrhiza, white peony root, ginger, and mint. It can be used for soothing the liver, strengthening the spleen, and enriching blood and menstruation (Zhang and Lu, 2013). In a study on the pharmacology of Xiaoyao powder used to treat normal and gonadectomy mice, Wang et al. (2003) reported that the Xiaoyao powder significantly increased the uterus weight of both control and gonadectomy mice $(P<0.01)$ and improved the estradiol level $(P<0.05)$, revealing that Xiaoyao powder has estrogen-mimicking effects (Wang et al., 2003). Our previous studies using an ovariectomized mice model have also proven that Xiaoyao powder has estrogenic properties. In this study, we investigated the effects of three flavonoid components of Xiaoyao powder on the proliferation of MCF-7 cells, and protein and mRNA expression of ER $\alpha$ and ERß. The changes were detected after the active plant estrogen was blocked by $\mathrm{ICl} 182780$. We have initially confirmed the effects of flavonoid components in Xiaoyao powder and provided an experimental reference for its use in the treatment of climacteric syndrome.

\section{MATERIAL AND METHODS}

\section{Materials}

\section{Cell lines}

The ER-positive human breast cancer cell line MCF-7 was supplied by a source center of Beijing, Xiehe.

\section{Drugs}

The purity of quercetin was $98 \%$ and the Chemical Abstract Service (CAS) number was ZL0083105. The purity of kaempferol was $98 \%$, and its CAS number was ZL01290822. The purity of isorhamnetin was $98 \%$, and its CAS number was ZL01900218. The chemicals were purchased 
from Nanjing Zelang. The estradiol purity was $98 \%$, and the CAS number was L750N46. It was purchased from Bai Ling Wei. The estrogen antagonist ICl182780 purity was $99 \%$, the CAS was 20A/129473, and it was obtained from Tocris Bioscience.

\section{Reagents}

Dulbecco's modified Eagle's medium (DMEM) high glucose, non-phenol red DMEM, charcoal/dextran-treated fetal bovine serum (CDT-FBS), and trypsase were purchased from the HyClone company. Dilmethly sulfoxide (DMSO) and 3-(4,5-dimethylthiazol-2-yl)-2,5diphenyltetrazolium bromide (MTT) were purchased from Sigma. The anti-human mice monoclone antibodies of ERa and ER $\beta$ were obtained from Santa Cruz, and the anti-mice goat IgG was purchased from Wuhan Boster. Trizol and the diethylpyrocarbonate water were purchased from Gibco. The PCR kit and primers were from Shanghai Sangon.

\section{Instruments}

HF-90 incubator (Shanghai Lixin instrument Company), Olympus inverted microscope (Japan Olympus), TGL-16G-C High speed refrigerated centrifuge (Shanghai Anting Science Instrument Company, PCR amplification instrument (Germany Biometra), enzyme-linked immunosorbent assay (ELISA) microplate reader (Shanghai Thermoelectricity Company), Nano-100 micro-spectrophotometer (Hangzhou Aosheng Instruments Company), DYY-10C electrophoresis apparatus (Beijing Liu yi Instrument Company), Chan1Gel15000 gel imaging system (Beijing Sai zhi chuang zhi Technology Company), SmartChemill integrated chemiluminiscence imaging instruments (Beijing Sai zhi chuang zhi Technology Company).

\section{Methods}

\section{Drug preparation}

The estradiol (5.5 mg) was weighed and dissolved in $4 \mathrm{~mL}$ absolute ethyl alcohol. Then, $20 \mu \mathrm{M}$ storage solution was prepared using non-phenol red DMEM. It was then diluted to $10^{-6} \mu \mathrm{M}$. ICl182780 $(1.0 \mathrm{mg})$ was weighed, and its storage solution was prepared with non-phenol red DMEM $(200 \mu \mathrm{M})$. It was then diluted to $0.1 \mu \mathrm{M}$. Then, $3.0 \mathrm{mg}$ quercetin, $5.8 \mathrm{mg}$ kaempferol, and $6.4 \mathrm{mg}$ isorhamnetin were weighed separately and dissolved in non-phenol red DMEM to make a $200 \mu \mathrm{M}$ storage solutions. They were further diluted to make six different concentrations ranging from $10^{-3}-100 \mu \mathrm{M}$.

\section{Cell culture}

Human breast cancer MCF-7 cells were cultured using DMEM with high glucose (including $10 \% \mathrm{FBS}$ ) and cultured at $37^{\circ} \mathrm{C}$ and $5 \% \mathrm{CO}_{2}$. The cells were washed with phosphate buffered saline (PBS) 2-3 times per day 4 days before the experiment. Then, they were cultured with nonphenol red DMEM (containing 5\% CDT-FBS).

\section{MTT assay}

MCF-7 cells were seeded on 96-well plates at a density of 6000 cells/well with non-phenol 
red DMEM for 4 days until reaching the logarithmic phase of growth. Then, $200 \mu \mathrm{L}$ DMEM was added to each well and cells were treated with drugs after $24 \mathrm{~h}$. The following groups were investigated: blank control group, positive control group $\left(10^{-6} \mu \mathrm{M}\right.$ estradiol), experimental drug groups (different concentrations of quercetin, kaempferol, and isorhamnetin), and each group consisted of 6 wells. MTT was added after treatment for $48 \mathrm{~h}$ and lysing the cells with DMSO. The absorption value of each well was measured at $490 \mathrm{~nm}$ using an ELISA microplate reader at an optical density (OD) of $490 \mathrm{~nm}$, and then the average absorption value and proliferation rate $(\mathrm{PR})$ were calculated. $\mathrm{PR}=$ experimental group / blank control group x $100 \%$.

\section{Antagonistic experiment}

The cells were divided into a blank control group, positive control group (10-6 $\mu \mathrm{M}$ estradiol), positive control $+\mathrm{ICl} 182780$ group, active plant estrogen group (10-2 $\mu \mathrm{M}$ quercetin, $100 \mu \mathrm{M}$ kaempferol, $10^{-3} \mu \mathrm{M}$ isorhamnetin), and active plant estrogen+ICl182780 group, with each group seeded in 6 wells. The cells were pretreated with $0.1 \mu \mathrm{M} \mathrm{ICl} 182780$ for $48 \mathrm{~h}$. Then, MTT was added and the cells were lysed using DMSO. The absorption value of each well was measured at $490 \mathrm{~nm}$ using an ELISA microplate reader (OD 490), and then the average absorption value and PR were calculated.

\section{Protein expression of ERa and ER $\beta$ in MCF-7 cells}

MCF-7 cells were seeded on 10-cm culture dishes at a density of $1 \times 10^{6}$ cells/dish with non-phenol red DMEM and cultured for 4 days until reaching the logarithmic phase of cell growth. The drugs were changed after $24 \mathrm{~h}$. Each group consisted of three dishes. They were divided into a blank control group, positive control group $\left(10^{-6} \mu \mathrm{M}\right.$ estradiol), positive control $+\mathrm{ICI} 182780$ group, active plant estrogen group $\left(10^{-2} \mu \mathrm{M}\right.$ quercetin, $100 \mu \mathrm{M}$ kaempferol, $10^{-3} \mu \mathrm{M}$ isorhamnetin), and active plant estrogen+ICl182780 group. The cells were pretreated with $0.1 \mu \mathrm{M} \mathrm{ICI} 182780$ for $1 \mathrm{~h}$. After $48 \mathrm{~h}$, the cells were lysed using lysis buffer, and their protein was extracted. A 10\% sodium dodecyl sulfate polyacrylamide gel electrophoresis (SDS-PAGE) was used to separate different proteins according to the target protein. The electrophoresis condition was $100 \mathrm{~V}$ for 90 min. The common wet transmembrane condition was $270 \mathrm{~mA}$ for $2 \mathrm{~h}$. Then, the membrane was blocked with $5 \%$ non-fatty milk for $1 \mathrm{~h}$. The antibodies of $\beta$-actin, ERa, and ER $\beta$ were diluted $1: 300$, and the membranes were incubated for $2 \mathrm{~h}$ at room temperature. Then, the secondary antibodies were diluted 1:3500, and the membranes were incubated for $1 \mathrm{~h}$ at room temperature. An electrochemiluminescence was used to develop the membrane. The Land ID gel-imaging system was used to analyze the results. The gray value rates of $E R \alpha / \beta$-actin and $E R \beta / \beta$-actin were calculated to show the protein expression level.

\section{mRNA expression of ERa and ERß in MCF-7 cells}

The cells were seeded and cultured as previously described. After treating with drugs for $48 \mathrm{~h}$, the total RNA in each group was extracted according to the manufacturer instructions using Trizol, and the Nano-100 micro-spectrophotometer was used to detect the A260 and A280 values. The RNA was acceptable when the A260/A280 value was in the range of 1.8-2.0, and then the total RNA was calculated. RNA $(5 \mu \mathrm{g})$ was reverse transcribed to obtain cDNA using the 
following reaction conditions: $25^{\circ} \mathrm{C} 10 \mathrm{~min}, 42^{\circ} \mathrm{C} 60 \mathrm{~min}$, and $70^{\circ} \mathrm{C} 10 \mathrm{~min}$. $\beta$-actin was used as the reference gene, and the primer sequences are shown in Table 1. The PCR amplification conditions were as follows: predenaturation at $94^{\circ} \mathrm{C}$ for $2 \mathrm{~min}$; denaturation at $94^{\circ} \mathrm{C}$ for $30 \mathrm{~s}$; annealing for 40 $\mathrm{s}\left(\mathrm{ERa} 56.5^{\circ} \mathrm{C}, \mathrm{ER} \beta 54^{\circ} \mathrm{C}\right.$, and $\beta$-actin $\left.56^{\circ} \mathrm{C}\right)$, and stretching at $72^{\circ} \mathrm{C}$ for $40 \mathrm{~s}$ for 35 cycles. The termination was performed at $72^{\circ} \mathrm{C}$ for $10 \mathrm{~min}$. A $1.5 \%$ agarose gel was used to separate bands at $120 \mathrm{~V}$ for $30 \mathrm{~min}$. The gel-pro gel analysis system was used to analyze the gel bands. ERK $1 / \beta-$ actin, ERK2/ $\beta$-actin, and JNK2/ $\beta$-actin were calculated.

Table 1. PCR primers.

\begin{tabular}{l|l|l|c}
\hline Gene & Upstream $\left(5^{\prime}-3^{\prime}\right)$ & Downstream $\left(5^{\prime}-3^{\prime}\right)$ & Product length (bp) \\
\hline$\beta$-actin & CGTGGACATCCGCAAAGAC & AAGAAAGGGTGTAACGCAACTA & 302 \\
\hline ER $\alpha$ & CAGGCTTTGTGGATTTGACC & AGAGACTTCAGGGTGCTGGA & 313 \\
\hline ER $\beta$ & AGCACGGCTCCATATACATACC & TGGACCACTAAAGGAGAAAGGT & 202 \\
\hline
\end{tabular}

\section{Statistical analysis}

The SPSS 19.0 software was used to analyze the data, and the ANOVA, LSD, and SNK methods were used for comparisons among groups. All data are reported as means $\pm S D$, and a $P$ $<0.05$ was considered statistically significant.

\section{RESULTS}

\section{Effects on cell proliferation}

The cell proliferation results are shown in Table 2 . Treatment with quercetin at concentrations of $100 \mu \mathrm{M}(\mathrm{P}<0.05)$ and $10 \mu \mathrm{M}(\mathrm{P}<0.05)$ significantly inhibited the proliferation of MCF-7 cells compared with the control group, which suggested that these concentrations were toxic to the cells and were not suitable for further experimentation. Treatment with $10^{-2}$ and $10^{-3} \mu \mathrm{M}$ quercetin $(\mathrm{P}<$ $0.05), 100$ and $10^{-2} \mu \mathrm{M}$ kaempferol $(\mathrm{P}<0.01)$, and $10^{-3} \mu \mathrm{M}$ isorhamnetin significantly promoted cell proliferation. The effects were the same as treatment with estradiol, and the proliferation rates were in the range of $8-22 \%$. Treatment with other concentrations of the drugs had no significant effects.

\section{Effects of ICl182780 on the roles of three flavonoid components in promoting cell proliferation}

The results are shown in Table 3. Compared with the blank control group, the estradiol significantly promoted the proliferation of MCF-7 cells, with cells exhibiting a proliferation rate of $125 \%$ ( $P<0.01)$. Quercetin, kaempferol, and isorhamnetin significantly promoted cell proliferation, with proliferation rates of 122,128 , and $121 \%$, respectively $(P<0.01)$. Compared with the positive control group, ICl182780 reversed the proliferation effects of estradiol, with a rate of $113 \%$ ( $\mathrm{P}<$ 0.05). Compared with the quercetin group, ICl182780 reversed the proliferation effects of quercetin, and the rate was $111 \%(P<0.05)$. Compared with kaempferol, ICI182780 reversed the proliferation effects of kaempferol, and the rate was $119 \%(P<0.05)$. Compared with isorhamnetin, ICI182780 reversed the proliferation effects of isorhamnetin, and the rate was $113 \%(P<0.05)$. 
Table 2. Effects of three flavonoid components in Xiaoyao powder on cell proliferation (mean $\pm S D, N=6$ ).

\begin{tabular}{l|c|c|c}
\hline Group & Concentration $(\mu \mathrm{M})$ & Absorption value PR\% & 100 \\
\hline Blank control & & $0.496 \pm 0.026$ & $113^{*}$ \\
\hline Positive control & $10^{-6}$ & $0.558 \pm 0.016^{*}$ & $92^{*}$ \\
\hline Quercetin & 100 & $0.456 \pm 0.033^{*}$ & $89^{*}$ \\
\hline & 10 & $0.443 \pm 0.032^{*}$ & 97 \\
\hline & 1 & $0.480 \pm 0.022$ & 103 \\
\hline & $10^{-1}$ & $0.510 \pm 0.018$ & $108^{*}$ \\
\hline Blank control & $10^{-2}$ & $0.535 \pm 0.016^{*}$ & $108^{*}$ \\
\hline Positive control & $10^{-3}$ & $0.536 \pm 0.019^{*}$ & 100 \\
\hline Kaempferol & & $0.444 \pm 0.062$ & $116^{*}$ \\
\hline & $10^{-6}$ & $0.516 \pm 0.039^{*}$ & $255^{* *}$ \\
\hline & 100 & $1.133 \pm 0.085^{* *}$ & 102 \\
\hline \multirow{2}{*}{ Blank control } & 10 & $0.451 \pm 0.053$ & 88 \\
\hline Positive control & 1 & $0.390 \pm 0.012$ & 87 \\
\hline Isorhamnetin & $10^{-1}$ & $0.385 \pm 0.056$ & $121^{* *}$ \\
\cline { 2 - 4 } & $10^{-2}$ & $0.539 \pm 0.075^{* *}$ & 96 \\
\hline & $10^{-3}$ & $0.425 \pm 0.043$ & 100 \\
\cline { 2 - 4 } & $10^{-6}$ & $0.527 \pm 0.038$ & $119^{* *}$ \\
\cline { 2 - 4 } & 100 & $0.626 \pm 0.048^{* *}$ & 104 \\
\cline { 2 - 4 } & 10 & $0.547 \pm 0.038$ & 108 \\
\hline
\end{tabular}

Compared with blank control group, ${ }^{*} P<0.05,{ }^{* *} \mathrm{P}<0.01$.

Table 3. Effects of ICl 182780 on the roles of three flavonoid components in promoting cell proliferation (mean \pm $\mathrm{SD}, \mathrm{N}=6)$.

\begin{tabular}{l|c|c|c}
\hline Group & Concentration $(\mu \mathrm{M})$ & Absorption value & PR\% \\
\hline Blank control & & $0.551 \pm 0.030$ & 100 \\
\hline Positive control & $10^{-6}$ & $0.692 \pm 0.039^{* *}$ & $125^{\star *}$ \\
\hline Positive control+ICl18278 & $10^{-6}+0.1$ & $0.625 \pm 0.076^{\#}$ & $113^{\#}$ \\
\hline Quercetin & $10^{-2}$ & $0.677 \pm 0.038^{* *}$ & $122^{* *}$ \\
\hline Quercetin+ICI182780 & $10^{-2}+0.1$ & $0.613 \pm 0.044^{\#}$ & $111^{\#}$ \\
\hline Kaempferol & 100 & $0.708 \pm 0.037^{\star *}$ & $128^{\star *}$ \\
\hline Kaempferol+ICI182780 & $100+0.1$ & $0.653 \pm 0.041^{\#}$ & $119^{\#}$ \\
\hline Isorhamnetin & $10^{-3}$ & $0.666 \pm 0.038^{* *}$ & $121^{* *}$ \\
\hline Isorhamnetin+ICI182780 & $10^{-3}+0.1$ & $0.622 \pm 0.031^{\#}$ & $113^{\#}$ \\
\hline
\end{tabular}

Compared with blank control group, ${ }^{*} \mathrm{P}<0.05,{ }^{* *} \mathrm{P}<0.01$; compared with active plant estrogen group, ${ }^{\#} \mathrm{P}<0.05$, ${ }^{\#} \mathrm{P}$ $<0.01$.

\section{Effects of three flavonoid components on the protein expression of ER $\alpha$ and ER $\beta$ in MCF-7 cells}

The western blotting results are shown in Figure 1A-C. Compared with the blank control group (lane a), the expression of ERa and ER $\beta$ in MCF-7 cells increased in the estradiol group (lane b). Treatment with quercetin, kaempferol, and isorhamnetin significantly increased the expression of the two proteins (lane $\mathrm{C}$ ), and the effects were the same as estradiol treatment. ICl182780 reversed the up-regulation of quercetin (Figure 1A, lane d), kaempferol (Figure 1B, lane d), and isorhamnetin (Figure $1 \mathrm{C}$, lane d), and the differences were statistically significant $(P<0.01)$. 


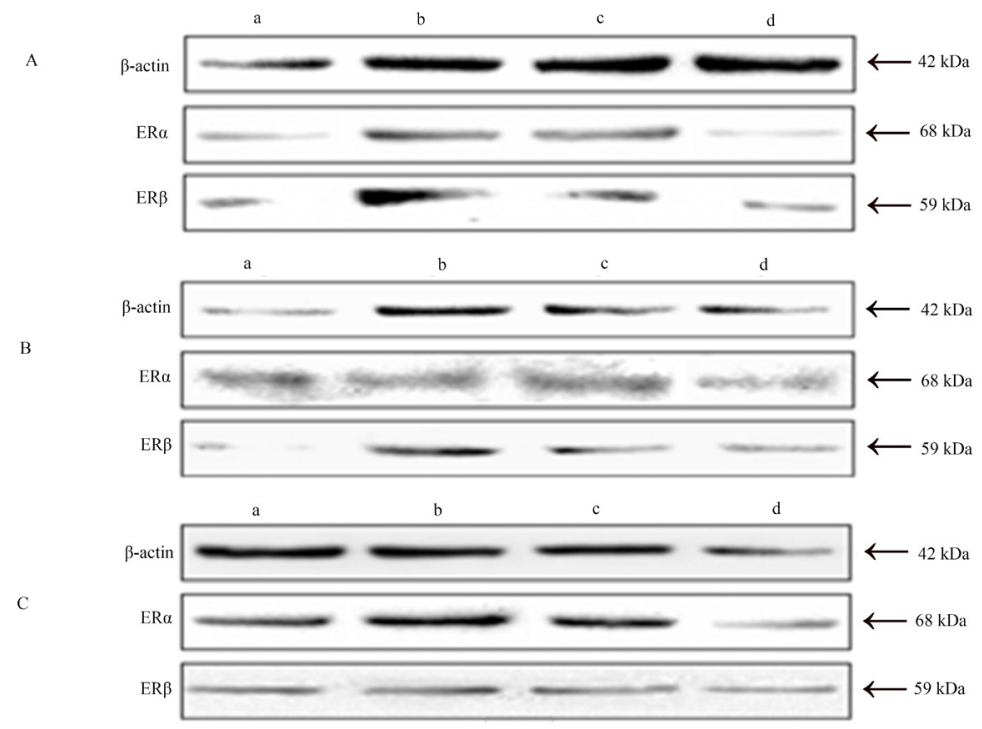

Figure 1. Effects of three flavonoid components on the protein expression of ERa and ER $\beta$ in MCF-7 cells. A. Quercetin group $(1 \mu \mathrm{M})$, B. Kaempferol group $(10 \mu \mathrm{M})$, C. Isorhamnetin group $(100 \mu \mathrm{M})$; lane a = blank control group; lane $b=$ positive control group; lane $c=$ active plant estrogen group; lane $d=$ active plant estrogen group $+\mid C l$ group . Comparison with blank group, ${ }^{*} \mathrm{P}<0.05,{ }^{* *} \mathrm{P}<0.01$; comparison with active plant estrogen group, ${ }^{\#} \mathrm{P}<0.05,{ }^{\# \#} \mathrm{P}<0.01$.

\section{Effects of three flavonoid components on the mRNA expression of ER $\alpha$ and ER $\beta$ in MCF-7 cells}

The results are shown in Table 4 and Figure 2A-C. Compared with the blank control group (lane a), the expression of ERa and ER $\beta$ mRNA in the MCF-7 cells increased in the estradiol group (lane b). Treatment with quercetin (Figure 2A, lane c), kaempferol (Figure 2B, lane C), and isorhamnetin (Figure $2 \mathrm{C}$, lane $\mathrm{C}$ ) significantly increased the expression of two kinds of mRNA, and the proliferation-promoting effects were the same as estradiol. ICl182780 reversed the upregulating effects of quercetin (Figure 2A, lane d), kaempferol (Figure 2B, lane d), and isorhamnetin (Figure $2 C$, lane $d)$, and the differences were statistically significant $(P<0.01)$.

\begin{tabular}{|c|c|c|c|}
\hline Group & Concentration $(\mu \mathrm{M})$ & $E R \alpha / \beta$-actin & $E R \beta / \beta$-actin \\
\hline Blank control & & $0.233 \pm 0.034$ & $0.438 \pm 0.040$ \\
\hline Positive control & $10^{-6}$ & $0.589 \pm 0.030^{* *}$ & $0.575 \pm 0.032^{\star *}$ \\
\hline Quercetin & 1 & $0.446 \pm 0.096^{* *}$ & $0.515 \pm 0.038^{*}$ \\
\hline Quercetin+ICI & $1+0.1$ & $0.332 \pm 0.031^{\#}$ & $0.379 \pm 0.038^{\# \#}$ \\
\hline Blank control & & $0.448 \pm 0.039$ & $0.614 \pm 0.031$ \\
\hline Positive control & $10^{-6}$ & $0.678 \pm 0.071^{* *}$ & $0.756 \pm 0.031^{* *}$ \\
\hline Kaempferol & 10 & $0.728 \pm 0.046^{* *}$ & $0.708 \pm 0.026^{\star \star}$ \\
\hline Kaempferol+ICl & $10+0.1$ & $0.510 \pm 0.035^{\# \#}$ & $0.559 \pm 0.061$ \\
\hline Blank control & & $0.430 \pm 0.044$ & $0.501 \pm 0.035$ \\
\hline Positive control & $10^{-6}$ & $0.718 \pm 0.066^{* \star}$ & $0.686 \pm 0.035^{\star \star}$ \\
\hline Isorhamnetin & 100 & $0.547 \pm 0.021^{*}$ & $0.562 \pm 0.028^{* \star}$ \\
\hline Isorhamnetin+ICl & $100+0.1$ & $0.486 \pm 0.008^{\# \#}$ & $0.497 \pm 0.007^{\# \#}$ \\
\hline
\end{tabular}

Comparison with blank control group, ${ }^{*} \mathrm{P}<0.05$, ${ }^{* *} \mathrm{P}<0.01$; comparison with active plant estrogen group, ${ }^{*} \mathrm{P}<0.05$, \# $\mathrm{P}<0.01$. 

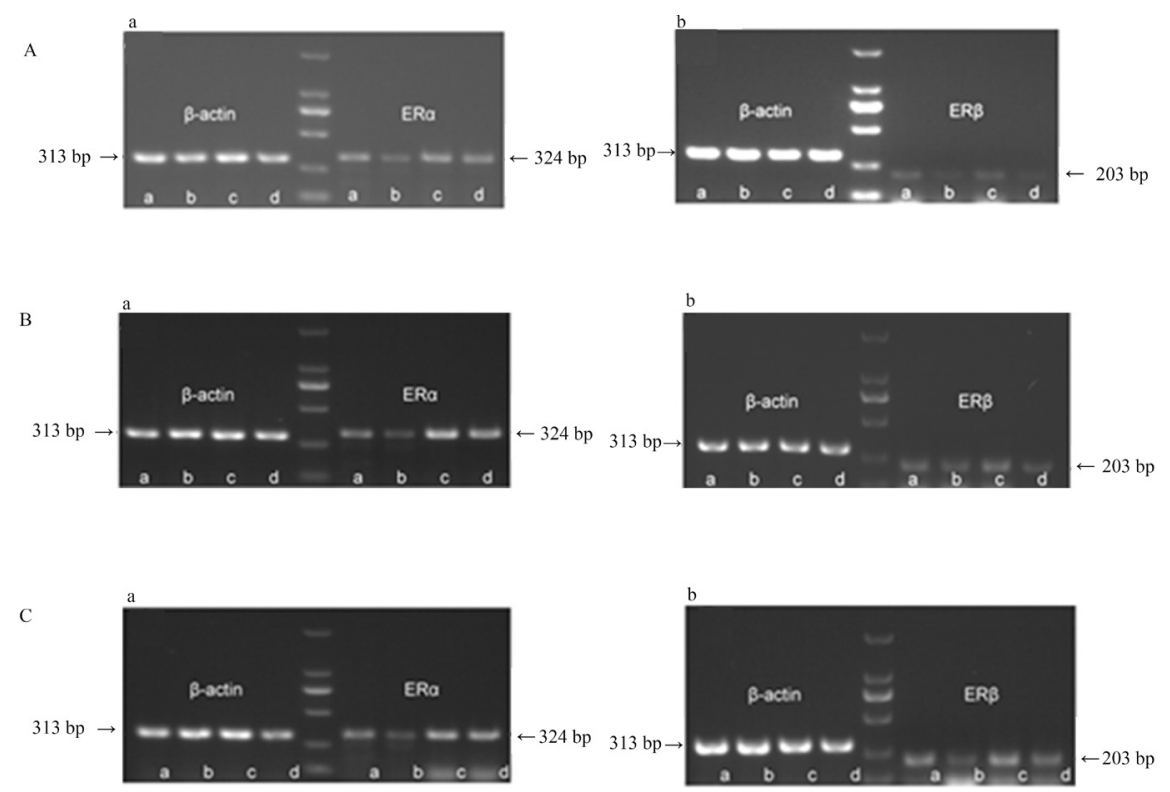

Figure 2. Effects of three flavonoid components on the mRNA expression of ER $\alpha$ and ER $\beta$ in MCF-7 cells. A. Quercetin group $(1 \mu \mathrm{M})$, B. Kaempferol group $(10 \mu \mathrm{M})$, C. Isorhamnetin group $(100 \mu \mathrm{M})$. Lane $a=$ blank control group; lane $b=$ positive control group; lane $c=$ active plant estrogen group; lane $d=$ active plant estrogen group $+\mathrm{ICl}$ group.

\section{DISCUSSION}

The E-screen selection method is a proliferation test for human breast cancer MCF-7 cells and is the classical evaluation method of estrogen activity in vitro. It can be used to detect estrogen effects and the strength of foreign estrogen. MCF-7 cells are human breast cancer cells with positive estrogen receptors, and estrogen or estrogen-like materials can combine with estrogen receptors to stimulate proliferation of MCF-7 cells. The experimental technique is simple, practical, and highly sensitivity. It is broadly applied for the fast selection and evaluation of plant estrogens (Payne et al., 2000). Hence, MCF-7 cells were used to evaluate cell proliferation in this study. The cell proliferation rates determined by MTT suggested that certain doses of quercetin, kaempferol, and isorhamnetin can promote cell proliferation, and the effect was similar to that of estradiol. These results suggested that the three flavonoid components in Xiaoyao powder have estrogen-like effects.

Plant components play estrogen-like roles depending on the mediation of the ERs (Mueller, 2002). ICl182780 is a kind of ER inhibitor and can decrease the effects of the signal transduction system that is mediated by a combination of estrogen and its receptors along with estrogenresponsive elements (Sommer et al., 2003). In this study, to further confirm whether three flavonoids components in Xiaoyao powder promoted the proliferation of MCF- 7 cells by acting on ERs, 0.1 $\mu \mathrm{M}$ ICl182780 was used to interfere with estradiol, quercetin, kaempferol, and isorhamnetin, and we found that their promoting effects were reversed by treatment with ICI182780. These results indicate that the proliferation-promoting effects of quercetin, kaempferol, and isorhamnetin might be mediated by ERs. 
ERs are members of the steroid receptors superfamily, and their transcription factors could combine with special DNA sequences to regulate gene expression (Tan and Wang, 2004). ERs can be divided into two subtypes of different gene coding: ER $\alpha$ and ER (Rong and Jin, 2005). Western blotting and RT-PCR were used in this study to measure the effects of quercetin, kaempferol, and isorhamnetin on the protein and mRNA expression of ER $\alpha$ and ER $\beta$ in MCF-7 cells. The results showed that isorhamnetin up-regulated the protein and mRNA expression of ER $\alpha$ and ER $\beta$, and these effects could be reversed by treatment with ICI182780. Further studies are needed to confirm that the flavonoid components in Xiaoyao powder have estrogen-like effects via mediation of ERs and can stimulate the mRNA and protein of ERs in MCF-7 cells. This preliminarily study proved the estrogen-like effects and mechanism of three flavonoid components in Xiaoyao powder, providing a theoretical reference for its use in treating climacteric syndrome.

\section{ACKNOWLEDGMENTS}

Research supported by the National Natural Science Foundation of China (General Progra, Grant \#81274035); the Heilongjiang Province Natural Science Foundation of China (Grant \#H201371 and \#D201275), and the Harbin Technological Innovation Projects (\#2015RQQXJ043).

\section{REFERENCES}

Lu HB, Yang XZ and Huang YX (2001). Status epidemiological studies of perimenopausal syndrome. GUANGXI Med. J. 23: 1131-1134.

Moutsatsou P (2007). The spectrum of phytoestrogens in nature: our knowledge is expanding. Hormones 6: $173-193$.

Mueller SO (2002). Overview of in vitro tools to assess the estrogenic and antiestrogenic activity of phytoestrogens. J. Chromatogr. B Analyt. Technol. Biomed. Life Sci. 777: 155-165.http://dx.doi.org/10.1016/S1570-0232(02)00282-9

Payne J, Jones C, Lakhani S and Kortenkamp A (2000). Improving the reproducibility of the MCF-7 cell proliferation assay for the detection of xenoestrogens. Sci. Total Environ. 248: 51-62.http://dx.doi.org/10.1016/S0048-9697(99)00479-9

Rong XS and Jin TY (2005). Research Advances on Estrogen Receptor. Occup Health \& Emerg Rescue 23: 11-14.

Sommer A, Hoffmann J, Lichtner RB, Schneider MR, et al. (2003). Studies on the development of resistance to the pure antiestrogen Faslodex in three human breast cancer cell lines. J. Steroid Biochem. Mol. Biol. 85: 33-47.http://dx.doi. org/10.1016/S0960-0760(03)00139-0

Song QW and Wang XG (2004). Progress perimenopausal syndrome phytoestrogens Prevention. Chin. J. Woman and Child Health Res. 6: 360-362.

Tan YF and Wang YL (2004). Advancement in Estrogen and Estrogen Receptor Signaling. Chin. J. Cell Biol. 26: $119-124$.

Tang CH, Yang XQ and Peng ZY (2002). Current Perspectives of Phytoestrogen (I) -Its chemical structure, classification and its contents in food. China Food Additives 3: 43-49.

Wang K, Chen WQ and Chen GR (2003). xiaoyao agents Pharmacodynamic studies and related Indications. Chongqing J. Res. Chin. Drugs and Herbs 1: 43-48.

Wei ZR (2009). Pathogenesis of peri menopausal syndrome and Research progress of drug treatment. Chin. Primary Health Care 7: 35-36.

Zhang Q and Lu WL (2013). Advances in modern pharmacological Xiaoyaosan Central South Pharmacy 7: 530-532. 